\title{
Electron Microscopic Study in the Gonadal Development in Early Human Embryos
}

\author{
By

\begin{abstract}
Osamu FUKUDA*, Yukihiko MIYAYAMA**, Toyoaki FUJIMOTO*** and Hitoshi OKAMURA*
\end{abstract}

\author{
Departments of Obstetrics and Gynecology* and Anatomy***, \\ Kumamoto University Medical School, Kumamoto 860, \\ Kumamoto University College of Medical Science**, \\ Kumamoto 862, Japan
}

-Received for Publication, December 3, 1987-

Key Words: Human embryo, Gonadal development, Primary sex cord, Primordial germ cells, Electron microscopy

\begin{abstract}
Summary: Human gonadal development was observed in early embryos by electron microscopy. In 5-week-old embryos, the genital ridge (GR) was forming with a single layered superficial epithelium, which consisted of two types of cells, clear and dark cells. In 6-week-old embryos, the swelling into the coelom of the GR was greatly increased. Primary sex cords (PSCs) were forming as columnar projections from the primitive cortex cells. The basal lamina appeared between the future cortex and medulla, indicating that PSCs are of cortex origin. The primordial germ cells (PGCs) completed their migration into the GR: many of them were incorporated, in PSCs. In 7-8-week-old embryos, the PSCs were well developed, and clear and dark cells were still distinguishable within the PSCs. Sex differentiation in the primitive gonad became discernible on a histologically basis. In the testis, the tunica albuginea appeared and PGCs were being incorporated in the PSCs and were associated with both clear and dark cells. In the ovary, the cortex was dominantly proliferated and in the zone demarcating the cortex and medulla, collagen fibers were observed. In male embryos at 9 weeks onwards, the PGCs located in the PSCs underwent some ultrastructural changes, and the PSCs were branching and their peripheral ends were anastomosing with each other to form the rete testis.
\end{abstract}

In the human embryo, primitive gonadal development is initiated by the formation of a genital ridge as a thickening of the coelomic epithelium in the area between the root of the dorsal mesentery and the mesonephric swelling at 5 to 6 weeks of gestation. The superficial epithelium of the genital ridge (originally the coelomic epithelium as mentioned above) then proliferates, and the underlying mesenchyma also proliferates, thus forming a swelling into the coelom as the gonadal anlage (genital ridge) (witschi, 1962,1970 ). Only a few previous investigations on human gonadal development have dealt with the fine morphology. Further, two theories have recently been put forward concerning the origin of the primary sex cord of the early gonad in mammals: one

Address for sending proofs: Osamu FUKUDA, M.D. Department of Obstetrics and Gynecology, Kumamoto University Medical School, Kumamoto 860, Japan 
is an epithelial origin, i.e. the cord is formed as a columnar protrusion of the superificial epithelium of the genital ridge (Kozhukhar, 1978, Berbenkova, 1981); and the other involves a mesonephric origin, i.e. the cells of the mesonephros contribute to the formation of the sex cord (mouse: Byskov, 1978, Fraedrich, 1979, Upadhyay et al., 1979, rabbit: Kinsky, 1979, Wartenberg, 1979, sheep: Zamboni et al., 1979). The aim of the present study was thus primarily to clarify the origin of the primary sex cord ultrastructurally.

The migration process of primordial germ cells (PGCs) from the yolk sac to the gonadal anlage and their morphology have well been studied both by light (Witschi, 1948) and electron microscopy (Fujimoto et al., 1977, Miyayama et al., 1977, Lin et al., 1982, Miyayama et al., 1984), although the fine morphological changes of the PGCs after their settlement in the primitive gonad have not yet been investigated. We therefore aimed secondarily to elucidate the changes or attitude of the PGCs after migration into the gonadal anlage and those incorporated in the forming sex cord.

The present study also examines the gonad formation as a whole with the emphasis on the relationship between the somatic element and germinal one as components of the gonad.

\section{Materials and Methods}

The materials used in the present study were human embryos, which were obtained by legal abortion, estimated to be at the 5 th week (5 embryos; crown-rump (C-R) length, 6-8 $\mathrm{mm}$ ), the 6th week ( 3 embryos; C-R length, 10-15 mm), the 7th week (2 embryos; C-R length, 18-20 mm), the 8th week (one female embryo; C-R length, 25 $\mathrm{mm}$ ), the 9 th week (one male fetus; C-R length, $30 \mathrm{~mm}$ ), and the 11 th week (one male fetus; C-R length, $61 \mathrm{~mm}$ ) of gestation. Permission to study these embryonic tissues was obtained from the patients concerned.

For electron microscopy, whole embryos were pre-fixed in 3\% glutaraldehyde with $0.05 \mathrm{M}$ cacodylate buffer ( $\mathrm{pH}$ 7.4) for one hour, and then a desired portion including the gonad of each embryo was excised. This was post-fixed in 1\%osmium tetroxide with $0.05 \mathrm{M}$ cacodylate buffer ( $\mathrm{pH} 7.4$ ) for approximately one hour. The specimens were dehydrated with an ethanol series, embedded in Epon 812, and ultrathin sections were cut. These sections were stained with uranyl acetate and lead citrate and observed under an Hitachi HU-12A transmission electron microscope. Parts of the specimens were processed into sections with a thickness of $1 \mu$ and stained with toluidine blue for light microscopy. The embryos after the 7 th week were identified for their sex by checking for heterochromatin by the quinacrine dehydrochloride mustard method (Gaál and László, 1974).

\section{Results}

At the 5th week, the genital ridge was forming as a swelling into the coelom by elongation of the single layered coelomic epithelium cells in the area between the root of the dorsal mesentery and the mesonephric swelling and by proliferation of the underlying mesenchymal cells. The superficial epithelium (initially the coelomic epithelium) of the genital ridge was composed of two types of cells, clear ones with a lower electron density and dark ones with a high electron density (Fig. 2). The cells of the genital ridge possessed many small or microvillus-like processes on their apical surfaces and the cell necks were tightly connected to each other with desmosomes. At this stage, many PGCs were migrating in the dorsal mesentery, reflect- 
ing the peak in their migration, although some had already reached the genital ridge.

In the late part of the 5th week to the 6th week, the superficial epithelium of the genital ridge became multiple (2-3) layered by proliferation and further elongation of the epithelial cells. The underlying mesenchymal cells were also more proliferated, so that the swelling into the coelom of the genital ridge became more prominent (Fig. 1-A). Clear and dark cells as described above were still distinguishable in the thickened superficial epithelium at around this stage and also at more advanced stages (see below).

Basal laminae appeared at the borderline between the thicknened epithelium (presumptive cortex of the gonad) and the underlying mesenchyma (presumptive medulla). With further advance of development, the cortex and medulla gradually became distinct and the cortex cells began to project as columns into the medullar portion, indicating the initial stage of formation of the primary sex cord (Figs. 1-B and 3). At this stage, almost all the PGCs had arrived in the gonadal anlage and were observed to exist in both the cortex and medulla.

Some PGCs migrating in the dorsal mesentery and coelomic angle were irregular in ameboid shape, extending out cytoplasmic processes. The PGCs often contacted with the neighboring somatic cells (clear and dark cells) with a close association between the two types of cells.

After settlement of the PGCs in the gonad, the intracytoplasmic glycogen of the cells, which was abundant at earlier stages, diminished or disappeared. The cell organellae of the PGCs, such as mitochondria, Golgi apparatus and rough surfaced endoplasmic reticulum, became well-developed at around the settlement of the cells.(Fig. 4)

In the 7th-week embryo, the formation of the primary sex cord was advancing by the growth of columnar protrusions from the cortex into the medulla (Figs. 1-C and 5). In these cords, throughout this stage, two types of cells, clear and dark, as observed in the early superficial epithelium of the genital ridge, were still distinguishable and were randomly arranged in the cord. The clear cells at this stage had more developed rough surfaced endoplasmic reticulum than those of earlier embryos.

The PGCs which had reached the gonadal primordium were being incorporated among the sex cord cells. They were arranged randomly in the cord, being in close contact with the adjacent cord cells, i.e. with clear and/or dark cells.

Around and on the outer surface of the primary sex cords, the basal laminae were formed, which demarcated the cord and the modullar portion of the developing gonad (Fig. 6). The formation of such basal laminae indicates that the primary sex cord is of epithelial (originally coelomic epithelium) origin. In the border-zone dividing the cortex and medulla, abundant collagen fibers also appeared.

With further development of the embryo, at 8 weeks onwards, the sex difference of the primitive gonad became discernible on a histological basis (Fig. 1-D) and by sex chromosome examination using the quinacrine fluorescence staining method. In the ovary at this stage, new cortex was developing, which then formed a markedly thickened zone between the superficial epithelium and the primary sex cord masses (Fig. 7). In this new cortex of the primitive ovary, some PGCs were still scattered among the cortex cells (Fig. 8).

The primary sex cords underwent changes in their initial structure during the period of development. The outline of each cord became indistinct and the spaces between the cords became narrow or disappeared, so that the cords contacted closely with each other or fused, forming irregularly arranged 
cell masses in the medullar part of the primitive gonad.

PGCs located among these cord cells contacted tightly with neighboring cord cells (Fig. 9). In contrast to earlier stages, intracytoplasmic glycogen was no longer recognizable in the PGCs located in the sex cords or new cortex and also the medulla (Figs. 8 and 9).

At the 9th week, sex differentiation to male distinguishable on a histological basis. The tunica albuginea was formed, demarcating the reconstructed superficial epithelium (primary cortex) from the developing medulla (including the well-developed sex cord groups) of the primitive testis (Fig. 1-E). The primitive testis at this stage is shown as a light microscopic image in Fig. 10. In this primitive testis, clear and dark cells were still seen in the sex cords and appeared not to have changed thier characteristics. The cytoplasm of the clear cells had rough endoplasmic reticulum (rER) and mitochondria as in the earlier stages. In the contact area between the PGC and the cord cell, various types of junction or so-called interdigitation were observed (Fig. 11). The nuclear part of some PGCs incorporated in the sex cords had changed somewhat in character: part of the nuclear membrane was stripped or bulged with cytoplasm (Fig. 12) and chromatin distribution was seen to be dispersed in the nucleus.

Some PGCs located outside the sex cords, in the medullar mesenchyma, revealed no such structural changes in the nuclear part but the cytoplasm of the PGCs had a high electron density with considerable numbers of ribosomes (Fig. 13).

The tunica albuginea appeared to attain maximum development during this week, and on the outer surface of the testis, a new epithelium with single layered flattened cells was reconstructed (Fig. 14).
In the male embryo at the 11 th week, the sex cords became condensed and extended into the medulla (Fig. 15). Furthermore, they were branching and their peripheral ends were anastomosing with each other to form the rete testis. It was found that the cytoplasm of the PGCs being incorporated among the cord cells possessed well-developed cell organellae. The nucleoli changed to resemble thick threads in appearance. Clear and dark cells, which constituted the sex cords, were still distinguishable as. in the earlier stages and contacted radomly with neighboring PGCs (Fig. 16).

\section{Discussion}

In terms of the general process of development of the human gonard, the present findings are similar to those of previous reports (Witschi, 1962, 1970). Concerning the origin of the primary sex cord in mammals, two different theories have been put forward. One is an epithelial origin (Kozhukar, 1978, Berbenkova, 1981) which explains the formation of the sex cord on the basis of proliferation and columnar projection of the coelomic epithelium occupying the area between the mesonephric swelling and dorsal mesentery. The other involves a mesonephric origin. It was proposed recently by several investigators (mouse: Byskov, 1978, Fraedrich, 1979, Upadhyay et al., 1979, rabbit. Kinsky, 1979, Wartenberg, 1979; sheep: Zamboni et al., 1979) and is based on the contribution of somatic cells of the mesonephros to the formation of the sex cord. In this connection, Upadhyay et al. (1979) stated that in the mouse, "Early in embryonic life cells migrate from the mesonephric tubules", while Zamboni et al. (1979) reported that cells which originated from the glomeruli of the mesonephros contributed to formation of the gonad.

The present ultrastructural study demon- 
strated that the primary sex cord in the human embryo is of epithelial origin, as discussed in detail later. With the settlement of PGCs in the genital ridge, the indifferent gonad undergoes differentiation through the formation of primary sex cords, and rearrangement of the mesenchymal cells of the future medulla.

The principal point at issue is the origin of the cells constituting the sex cord as outlined above. Wartenberg et al. (1978, 1981) reported that in the sex cord, clear and dark cells were present and that these cells became Sertoli's supporting cells. In their description, it was noted that cells of a similar type to the dark cells were detected among the somatic cells in the mesonephros, and these mesonephros originating cells moved inside the gonadal primordium, and then took part in the formation of the primary sex cords.

Based on our observations, the process of sex cord formation was as follows, indicating an epithelial origin for the sex cord.

a) The above-mentioned dark cells as well as clear cells were initially recognized in a single layered coelomic epithelium which was to become the genital ridge (its superficial epithelium). b) By columnar protrusion of this coelomic epithelium. in which both clear and dark cells were involved, the primary sex cord was formed. c) Immediately after the formation of the primary sex cord, the basal lamina appeared outside the cord, between the cord and the surrounding medullar mesenchyma. The existence of the basal lamina is an important demonstration of the epithlial origin of the cord.

Byskov (1978) reported that the somatic part of the gonadal anlage consisted of two kinds of cells, mesenchyma and cells of mesonephric origin. Wartenberg (1981) also noted that cells of mesonephric origin and of epithelial origin interacted with each other in the indifferent gonad, and that the basal lamina was lacking between the sex cord and the mesenchymal core. However, as mentioned above, the present results showed that even in the deep part of the medulla, there was a clear demarcation by the basal lamina on the outer surface of the sex cords. Thus, our observations support the theory of a cortex origin for the primary sex cords in humans. Further, we may have to investigate the attitude of the somatic cells of the mesonephros at the late stage of gonard formation as pointed out by Kozhukhar (1978) and Berbenkova (1981).

Mention should be made of the attitude of the PGCs after their settlement in the gonadal anlage. Just after the arrival of PGCs in the gonadal anlage, most of the cells were found to be located in the coelomic epithelium, the future superficial epithelium of the genital ridge, and the PGCs then became incorported in the primitive sex cord with the formation of the latter. On the other hand, PGCs were also found scattered in the developing medullar portion.

In the later stage, some slight differences appeared in the morphological features of the PGCs between those located in the cortex-or the cortex derived sex cord and those in the medullar part of the indifferent gonad. Regardless of sex, the PGCs located in the primary sex cords revealed some changes of the nuclear membrane and chromatin distribution as described under $\mathrm{Re}$ sults. These changes might be considered to reflect an acceleration of the metabolism of the PGCs towards the definitive germ cells, while some changes appeared to be an initial sign of degeneration as described in rodents by Akhtar and Sidiki (1979) and others.

There was a general tendency for the intracytoplasmic glycogen content of the PGCs to decrease or disappear with the advance of development, and this may imply that the glycogen was utilized as an 
energy source for PGC migration (Clawson and Domm, 1963, Fujimoto et al., 1977, Miyayama et al., 1977). The disappearance of intracytoplasmic glycogen as well as that of alkaline phosphatase activity on the surface of PGCs (McKay et al., 1953, Fujimoto et al., 1977, Miyayama et al., 1984) may be considered as one sign that the PGC is changing its nature towards a more advanced stage.

Concerning differences in the ultrastructural features of the PGCs in the male and female in the indifferent gonad, we were unable to reach any firm conclusions insofar as the stages examined here were concerned, and this problem remains to be solved in the future.

\section{References}

1) Akhtar, M. and Sidiki, Y.: Undifferentiated intratubular germ cell tumor of the tests. Cancer, 43: 2332-2339, 1979.

2) Berbenkova, B.: Correlations between the coelomic epithelium, the gonocytes and satellite cells in tissue cultures of the indifferent human gonad. No. 1 Folia Morphologica, XXIX: 28: 30, 1981.

3) Byskov, A.G.: The anatomy and ultrastructure of the rete system in the fetal mouse ovary. Biology of Reproduction, 19: 720$735,1978$.

4) Clawson, R.C. and Domm, L.V.: Developmental changes in glycogen content of primordial germ cells in chick embryos. Proc. Soc. Exp. Biol., 112: 533-537, 1963.

5) Fraedrich, J.: Licht- und elektronenmikroskopische Untersuchungen über den $\mathrm{Zu}$ sammenhang der Mesonephros und frühen Gonadenentwicklung der weißen Maus. Dissertation. Bonn, Med. Fak., 1979.

6) Fujimoto, T., Miyayama, Y. and Fuyuta, M.: The origin, migration and fine morphology of human primordial germ cells. Anat. Rec., 188: 315-330, 1977.

7) Gaál, M. and Làszló, J. : Fluorescent microscopic observations in epithelial cells of embryonic skin and their use in early sex determination. Acta Anat., 89: 31-38, 1974.

8) Kinsky, I.: Bildung des somatischen Gonadenblastems durch degenerierende Urnierenanteile des Kaninchens. Verh. Anat. Ges. (Innsbruck), 73: 403-406, 1979.
9) Kozhukhar, V.G.: Differentiation epithelium of primordial gonad in early human embryos. Archiv Anat. Histol. I. Embryol. 74. (4): 84-90, 1978.

10) Lin, T-H., Ukeshima, A., Maeyama, M. and Fujimoto, T.: Scanning electron microscopic study on human primordial germ cells during the migration period. Okajimas Folia Anat. Jpn., 59: 305-320, 1982.

11) McKay, D.G., Herteig, A.T., Adams, E.C. and Dazinger, S.: Histochemical observations on the germ cells of human embryos. Anat. Rec., 117:201-220, 1953.

12) Miyayama, Y., Fuyuta, M. and Fujimoto, T.: Ultrastructural observations on the origin, ameboid features and associations of human primordial germ cells. Acta Anat. Nipponica, 52: 255-268, 1977 (in Japanese).

13) Miyayama, Y., Miyayama, H. and Fujimoto, T. : Histo-cytochemical characteristics of primordial germ cells in human embryo. Okajimas Folia Anat. Jpn., 61: 133-152, 1984.

14) Upadhyay, S., Luciani, J.M. and Zamboni, L.: The role of the mesonephros in the development of indifferent gonads and ovaries of the mouse. Ann. Biol. Anim. Biochem. Biophys., 19: 1179-1196, 1979.

15) Wartenberg, H.: Human testicular development and the role of the mesonephros in the origin of a dual Sertoli cell system. Andrologia, 10: 1-21, 1978.

16) Wartenberg, H.: Der Mesonephros und die Gonadentwicklung. Verh. Anat. Ges. (Innsbruck), 73: 385-401, 1979.

17) Wartenberg, H. Differentiation and development of the testis. Burger, H. and de Krester, D., The Testis, 39-80, Raven Press, New York, 1981.

18) Witschi, E.: Migration of the germ cells of human embryos from the yolk sac to the primitive gonadal folds. Contrib. Embryol., 32 (No. 209): 67-80, 1948.

19) Witschi, E.: Embryology of the ovary. Grady, H.G. and Smith, D.E., The Ovary, Monographs in Pathology 3: 1-10, Williams and Wilkins, Baltimore, 1962.

20) Witschi, E.: Embryology of the testis. Rosemberg, E. and Paulsen, C.A., The human Testis, 3-10, Plenum Press, New York and London, 1970.

21) Zamboni, L., Bézard, J. and Mauléon, P.: The role of the mesonephros in the development of the sheep fetal ovary. Ann. Eiol. Anim. Biochem. Biophys., 19(4B) 1153-1178, 1979. 


\section{PLATES}




\section{Explanation of Figures}

\section{Plate I}

Fig. 1. Semi-schematic drawing of the gonadal development in the early human embryo, based on the present observations. 

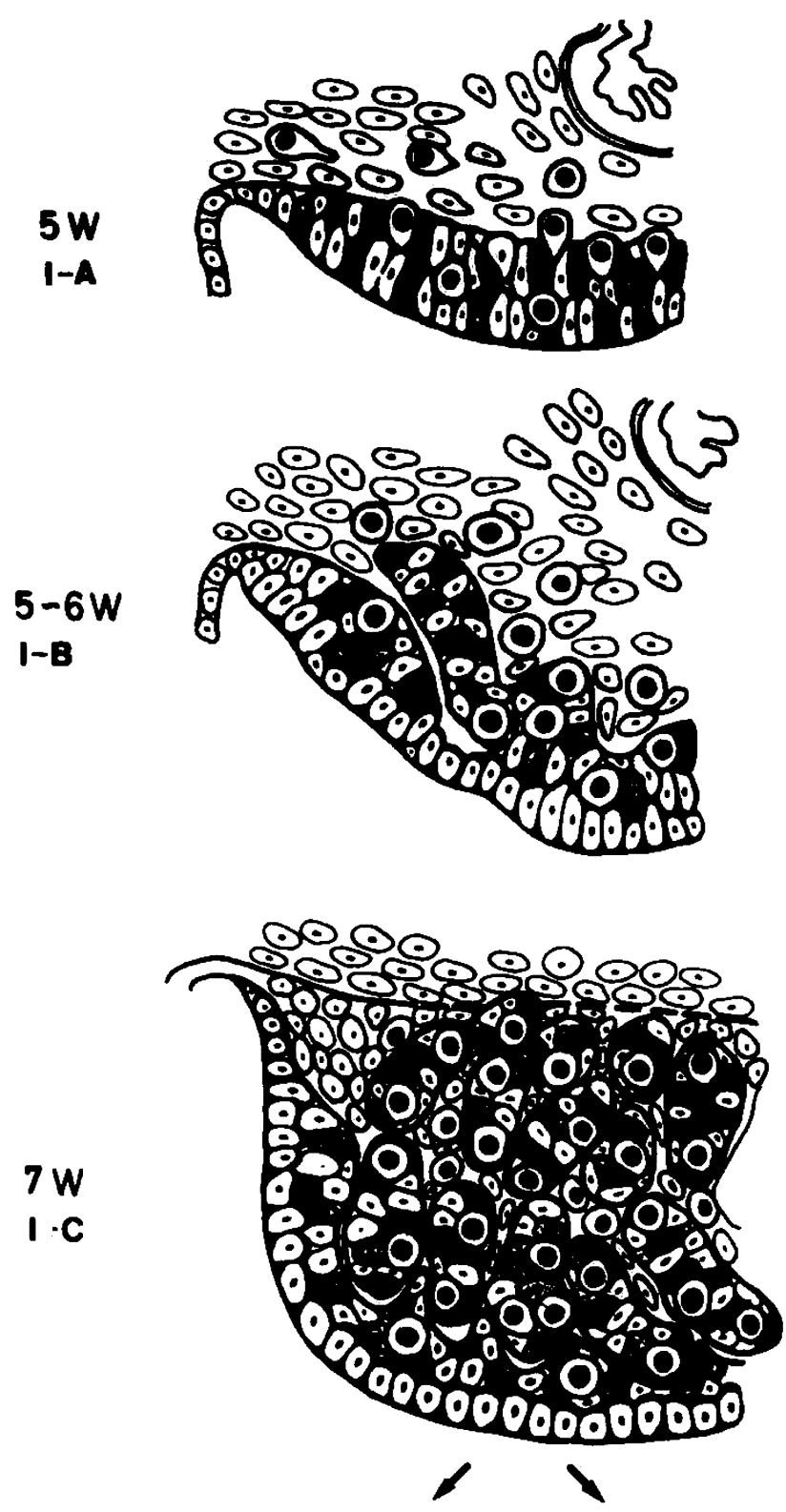

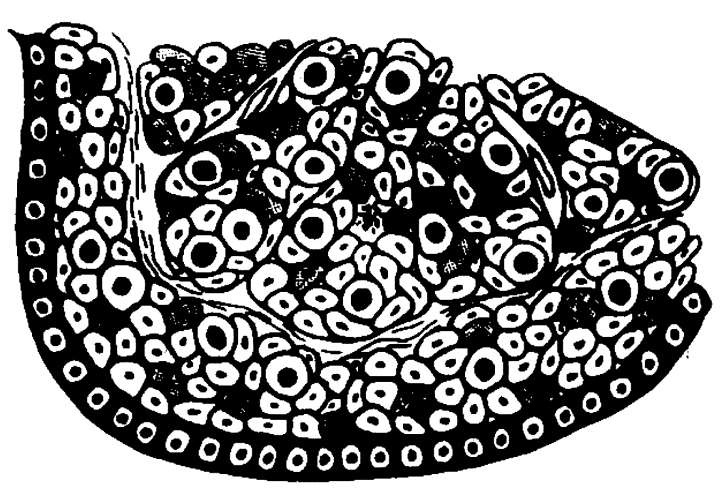

8W OVARY I-D

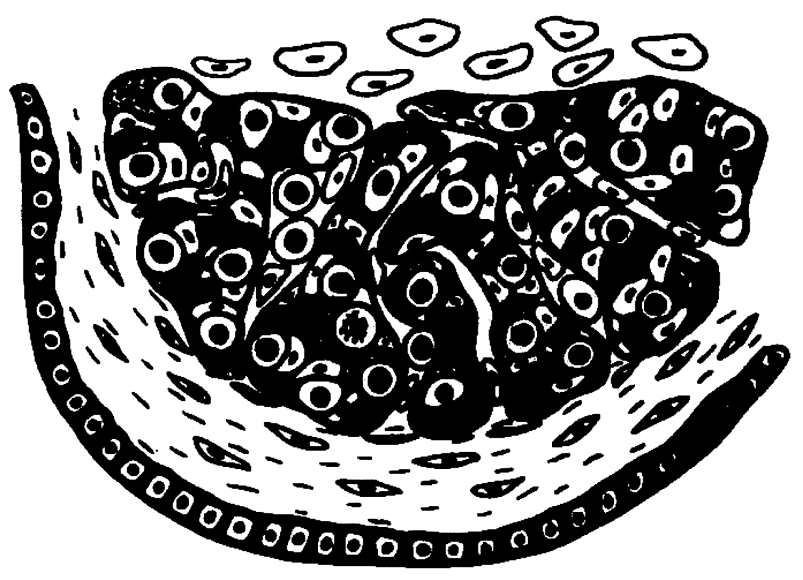

$9 W$ TESTIS I-E 


\section{Plate II}

Fig. 2. Electron micrograph of the epithelium of the genital ridge of a human embryo at the 5 th week (crown-rump (C-R) length, $6 \mathrm{~mm}$ ). Gr: genital ridge. $\times 5,500$

Fig. 3. Epithelium of the genital ridge of a human embryo in the late part of the 5 th week. The epithelial cells have become multiple layered by proliferation. Primordial germ cells (PGCs) are present in the cortex (arrows). (toluidine blue stain) $\times 820$ 
Plate II
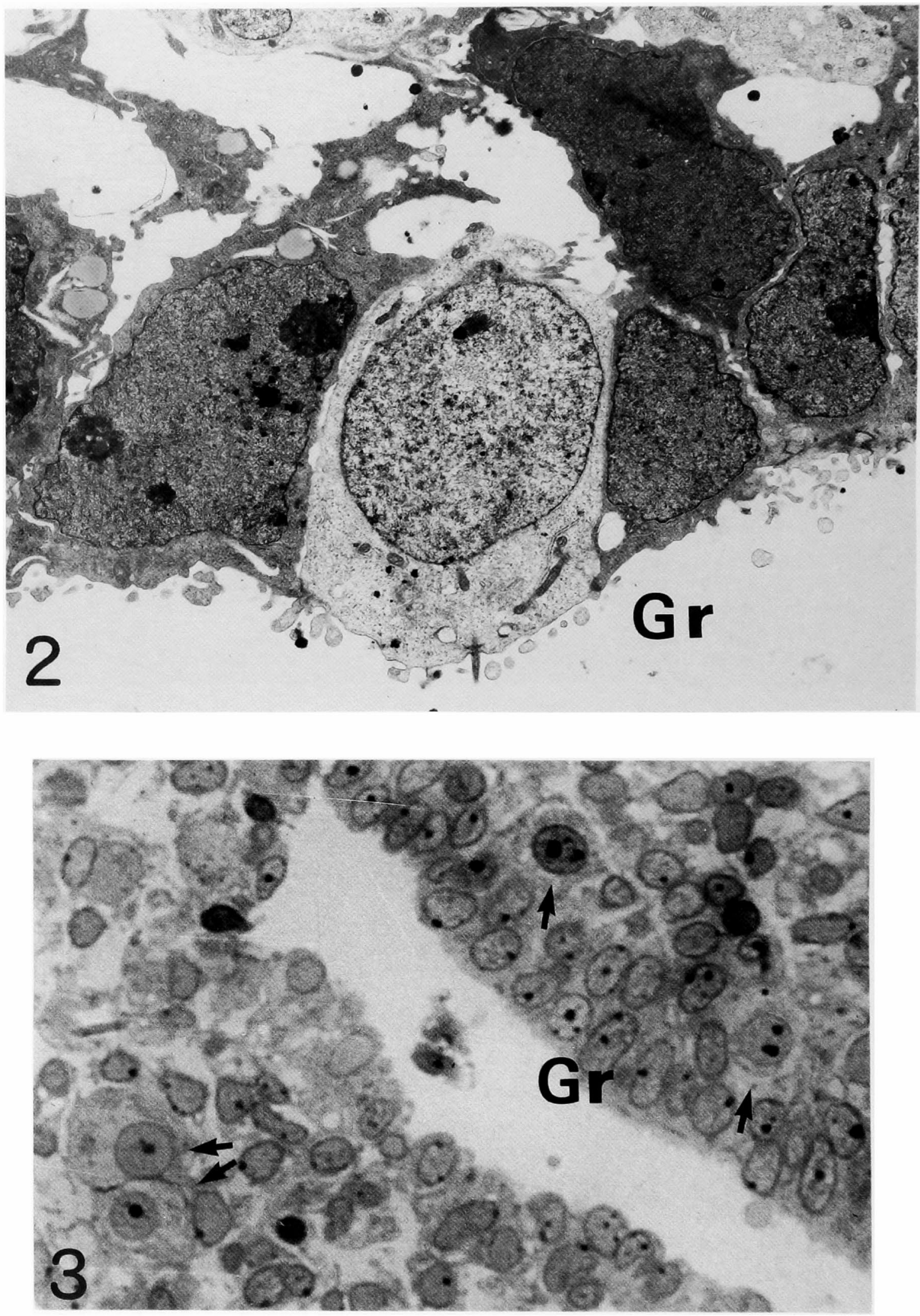


\section{Plate III}

Fig. 4. Electron micrograph of a PGC in the genital ridge of a human embryo at the 6th week (C-R length, $12 \mathrm{~mm}$ ). The PGC was surrounded by neighboring somatic cells with a close association between them. $\times 6,000$

Fig. 5. Sagittal section through the gonad (G) of a male embryo at the 7th week. Msn: mesonephros (H.E. stain). $\times 240$ 

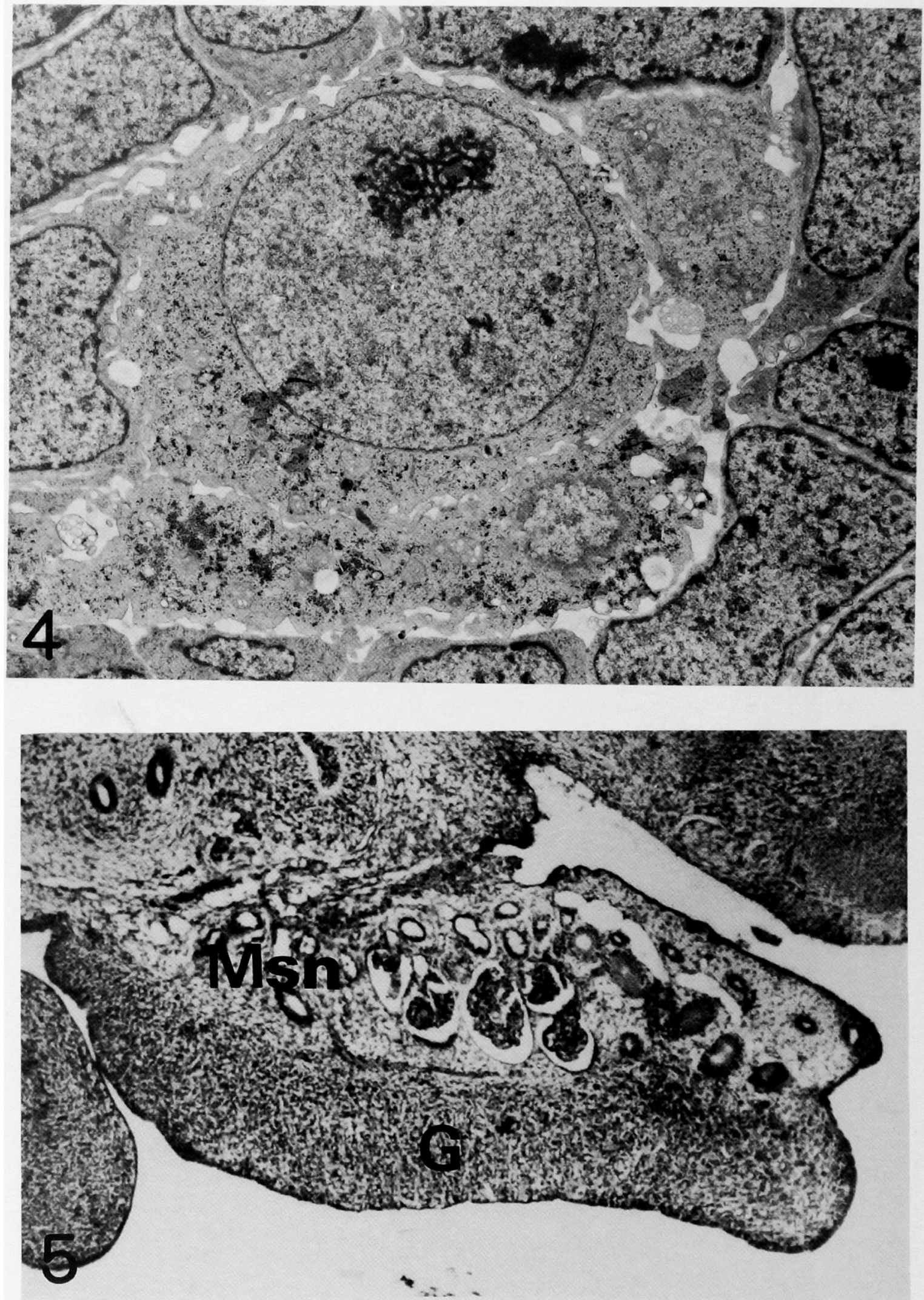


\section{Plate IV}

Fig. 6. Electron micrograph of the primitive gonad in the testis of a human embryo at the 7 th week (C-R length, $20 \mathrm{~mm}$ ).

Between the primary sex cord and medulla, the basal lamina (arrow) and collagen fibers can be observed. PSC: primary sex cord. $\times 22,000$

Fig. 7. Primitive gonad of a female embryo at the 8th week. New cortex is forming. (toluidine blue stain) $\times 250$

Fig. 8. Electron micrograph of the primitive ovary of a human embryo at the 8 th week (C-R length, $25 \mathrm{~mm}$ ). PGCs were found either in the cortex or the medulla (arrows). $\times 2,000$ 

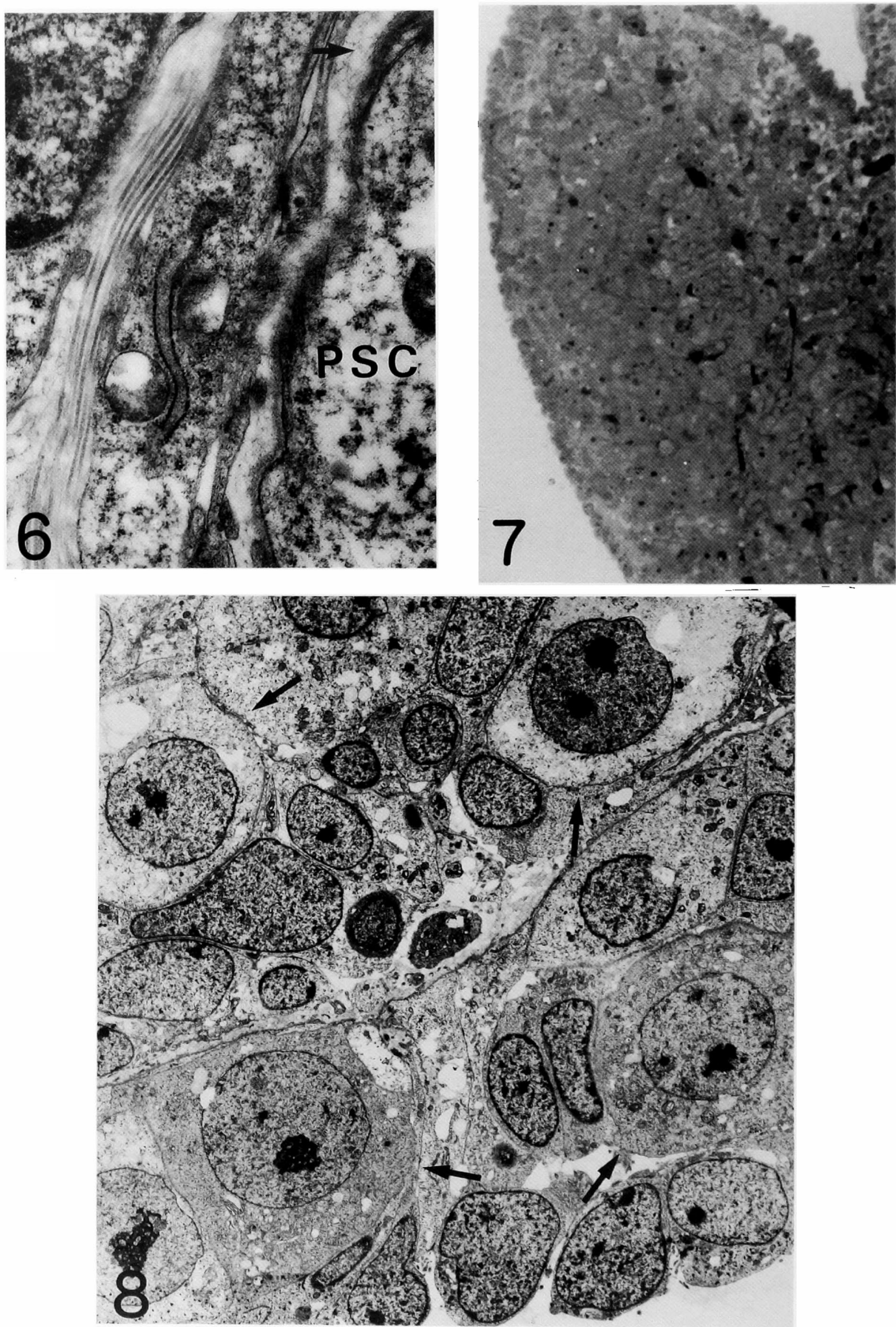


\section{Plate V}

Fig. 9. Electron micrograph of PGCs located in the primary sex cord in the ovary of a human embryo at the 8 th week $(C-R$ length, $25 \mathrm{~mm}$ ). The outline of each cord has become indistinct. $\times 3,000$

Fig. 10. Primitive gonad of a male embryo at the 9th week. Well-developed primary sex cords can be seen. (toluidine blue stain) $\times 330$

Fig. 11. Electron micrograph of the primary sex cord in the testis of a human embryo at the 9th week (C-R length, $30 \mathrm{~mm}$ ). In the contact area between the PGC and cord cell, a junction by interdigitation is found. $\times 48,000$ 

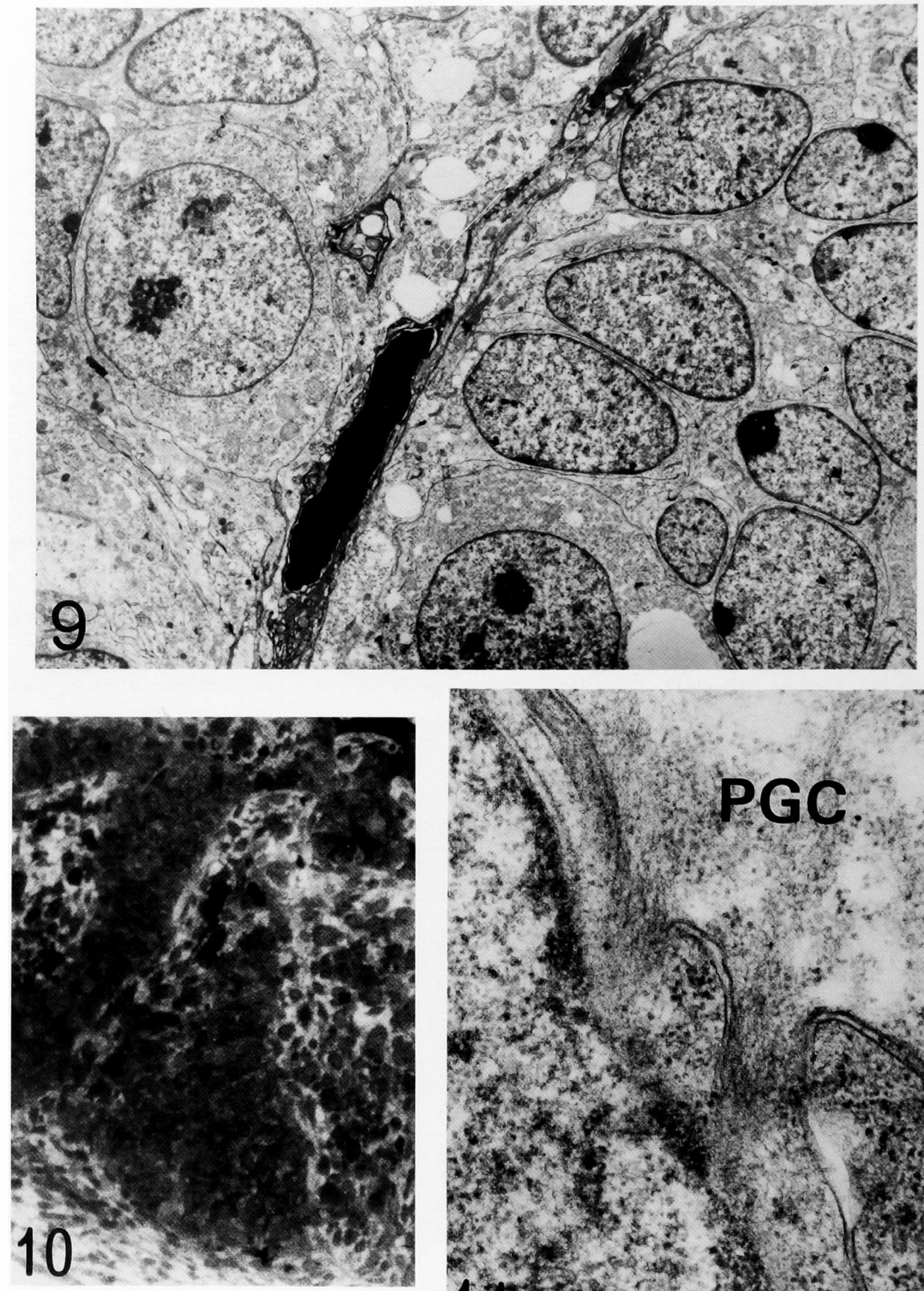

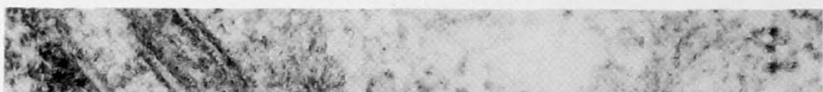

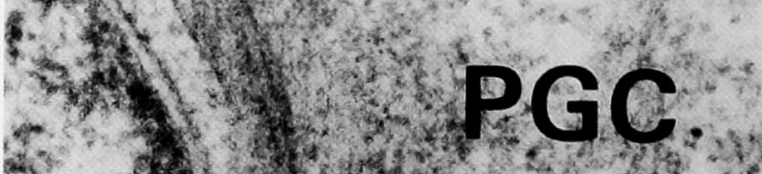

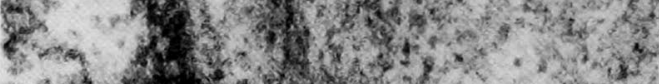

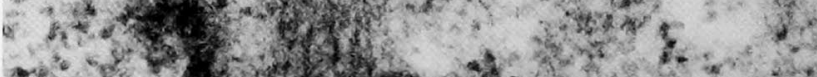

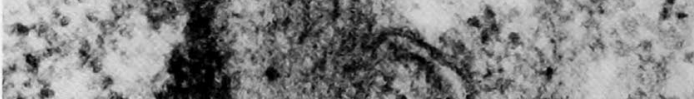

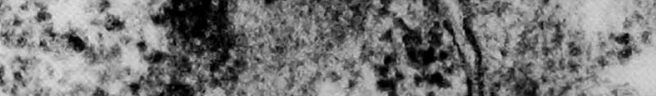

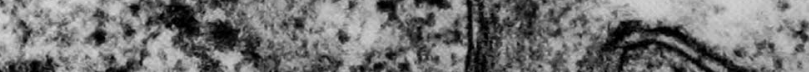

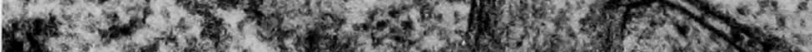

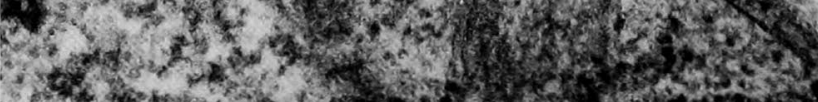

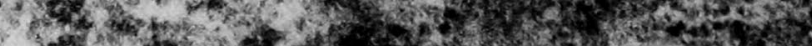
2.

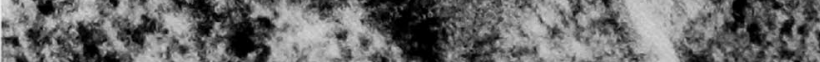

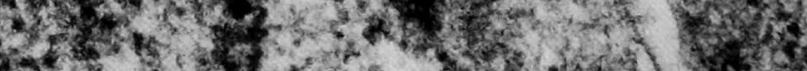

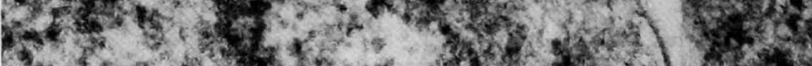

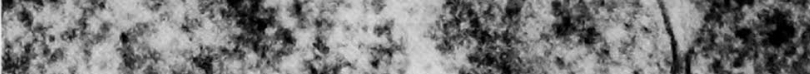

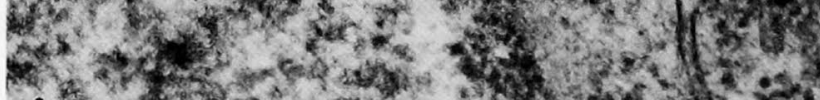
3. 


\section{Plate VI}

Fig. 12. Electron micrograph of the primary sex cord in the testis of a human embryo at the 9th week (C-R length, $30 \mathrm{~mm}$ ). Note the change to the nucleus in the PGC (arrow). $\times 3,000$

Fig. 3. Electron micrograph of PGCs located outside the sex cords (medulla) in the testis of a human embryo at the 9 th week (C-R length, $30 \mathrm{~mm}$ ). $\times 2,500$

Fig. 14. Electron micrograph of the tunica albuginea in the testis of a human embryo at the 9 th week (C-R length, $30 \mathrm{~mm}$ ). $\times 2,200$ 

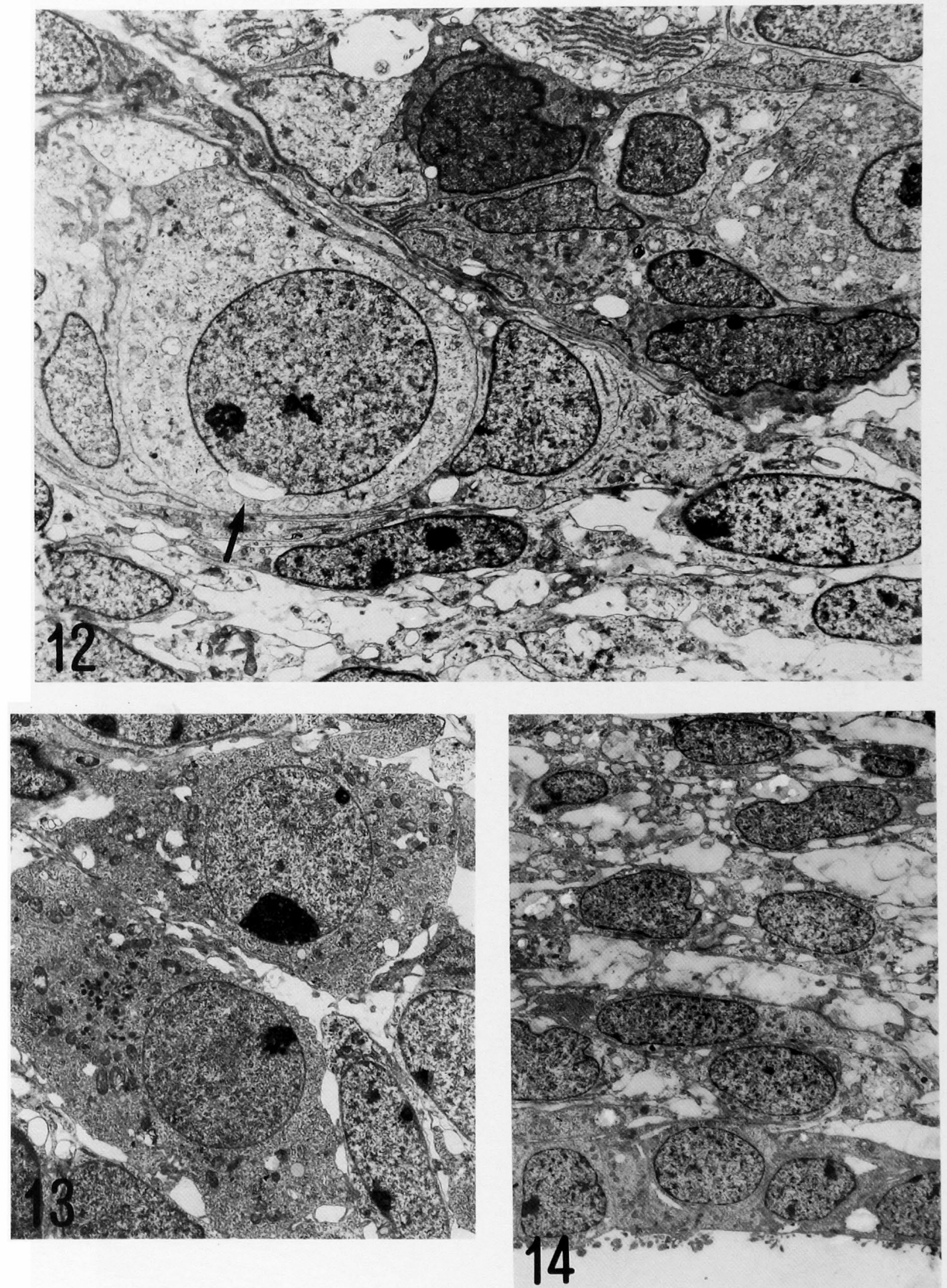


\section{Plate VII}

Fig. 15. Transverse section through the gonad of a male embryo at the 11 th week. The primary sex cords have condensed and extended into the medulla of the gonad. (H.E. stain) $\times 100$

Fig. 16. Electron micrograph of the primary sex cord in the testis of a human embryo at the 11th week (C-R length, $61 \mathrm{~mm}$ ). Note that the nucleoli are changed to resemble thick threads in appearance. $\times 4,100$ 

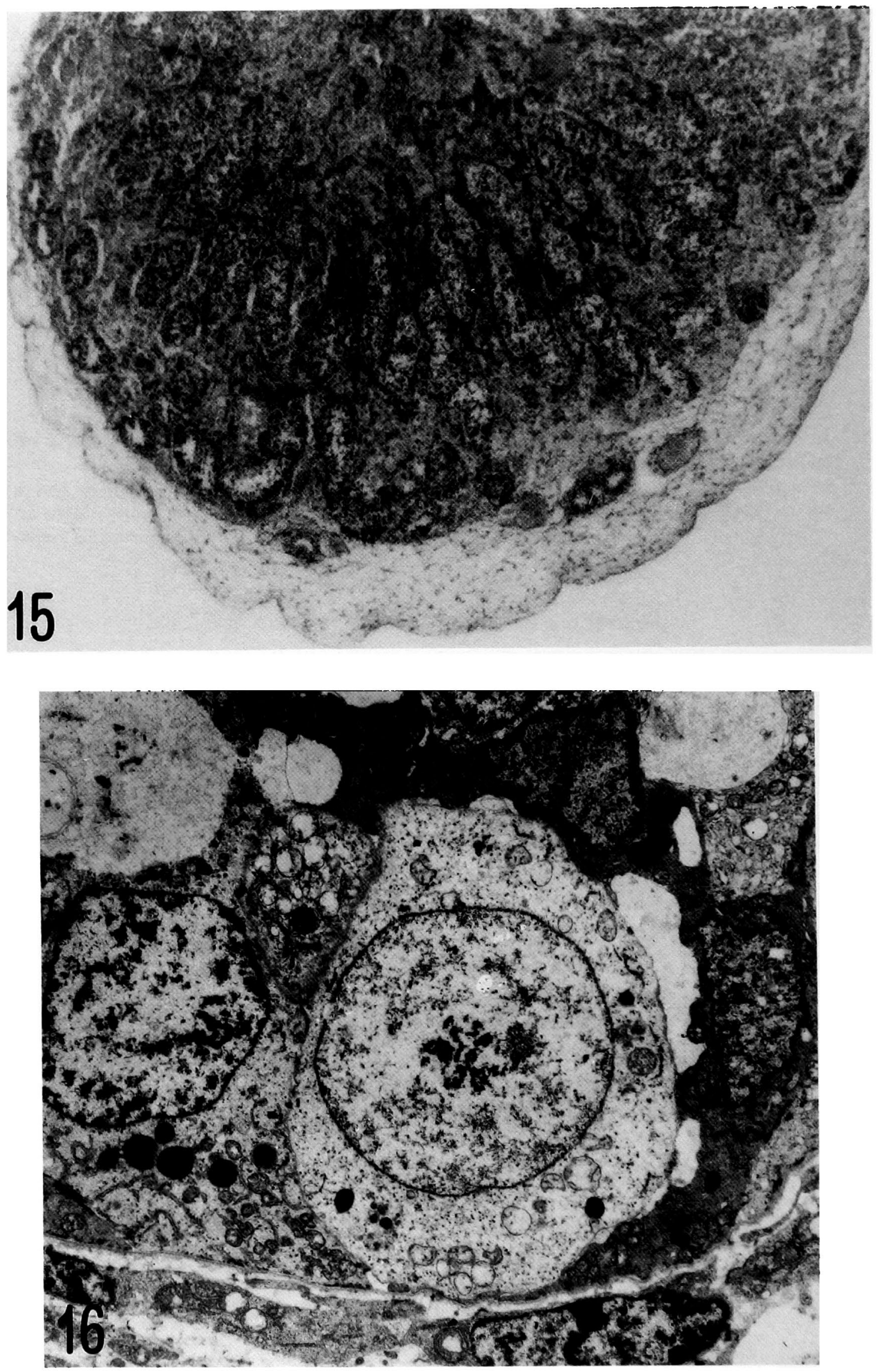